\title{
Influence of Iron on Cylindrocarpon Root Rot Development on Ginseng
}

\author{
Mahfuzur Rahman and Zamir K. Punja
}

First author: graduate student, and second author: professor, Department of Biological Sciences, Simon Fraser University, 8888 University Drive, Burnaby, British Columbia, V5A 1S6 Canada. Accepted for publication 12 June 2006.

\section{ABSTRACT}

Rahman, M., and Punja, Z. K. 2006. Influence of iron on Cylindrocarpon root rot development on ginseng. Phytopathology 96:1179-1187.

Cylindrocarpon root rot, caused by Cylindrocarpon destructans, is an important disease on ginseng (Panax quinquefolius) in Canada. We studied the effects of iron $(\mathrm{Fe})$ on disease severity and pathogen growth. When Hoagland's solution was amended with Fe at 56 and $112 \mu \mathrm{g} / \mathrm{ml}$ compared with $0 \mu \mathrm{g} / \mathrm{ml}$, disease initiation and final severity on hydroponically maintained ginseng roots was significantly $(P<0.0001)$ enhanced. Under field conditions, wounding of roots with a fine needle followed by application of $0.05 \%$ FeNaEDTA to the rhizosphere of treated plants significantly enhanced Cylindrocarpon root rot in 2003 and 2004 compared with unwounded roots with $\mathrm{Fe}$ or wounded roots without Fe. Foliar applications of $\mathrm{Fe}$ (as FeNaEDTA) to ginseng plants three times during the 2002 and 2003 growing seasons significantly increased Fe levels in root tissues. These roots developed larger lesions following inoculation with C. destructans in vitro. When radioactive $\mathrm{Fe}\left({ }^{59} \mathrm{Fe}\right)$ was applied to the foliage of ginseng plants, it was detected in the secondary phloem and in cortical and epidermal tissues within 1 week. Artificially wounded areas on the roots accumulated more ${ }^{59} \mathrm{Fe}$ than healthy areas. Diseased tissue also had threefold higher levels of phenolic compounds and Fe compared with adjoining healthy tissues. High-performance liquid chromatography analysis revealed enhanced levels of protocatechuic acid, chlorogenic acid, caffeic acid, ferulic acid, cinnamic acid, phloridizin, and quercetin. Phenolic compounds produced in diseased and wounded tissues sequestered $\mathrm{Fe}$ in vitro. The effects of $\mathrm{Fe}$ on mycelial growth, conidial germ tube length, and secondary branching of germ tubes of $C$. destructans were examined in vitro. When grown on Chrome-azurol $\mathrm{S}$ medium, $\mathrm{Fe}$ also was sequestered by $C$. destructans through siderophore production, which was visualized as a clearing pigmented zone at the margin of colonies. Mycelial dry weight was significantly increased in glucose/ yeast broth containing $\mathrm{Fe}$ at 56 or $112 \mu \mathrm{g} / \mathrm{ml}$. Conidial germ tube length and secondary branching of hyphae also were enhanced after 8 and $16 \mathrm{~h}$ by Fe. Colony growth of $C$. destructans was not enhanced by $\mathrm{Fe}$, but significantly greater spore production was observed with $\mathrm{Fe}$ at 56 and $112 \mu \mathrm{g} / \mathrm{ml}$ compared with no $\mathrm{Fe}$ in the medium. Although these levels of Fe had no effect on fungal pectinase enzyme activity, polyphenoloxidase (PPO) activity was significantly $(P<0.0001)$ enhanced. We conclude that $\mathrm{Fe}$ enhances Cylindrocarpon root rot through enhanced pathogen growth, sporulation, and PPO enzyme activity. Fe sequestered by phenolic compounds produced in wounded tissues can enhance Fe levels at the site of infection. The pathogen also has the ability to sequester $\mathrm{Fe}$ at these sites.
Iron $(\mathrm{Fe})$ is an essential micronutrient for plant growth, acting as an enzyme cofactor and participating in vital processes such as photosynthesis, DNA replication, and respiration. Fe also is important in microbial respiration and is sequestered from the surrounding environment for uptake by microbes by the production of siderophores. In root-infecting fungi, the role of Fe has been studied mainly from the perspective of its role in Pseudomonas-mediated biological control (27). For example, in diseases caused by Fusarium spp., disease suppressiveness was attributed to competition for $\mathrm{Fe}$ which limited fungal development (16). Scher and Baker (27) and Jones and Woltz (13) suggested that reduced $\mathrm{Fe}$ availability through $\mathrm{Fe}$ competition could reduce wilt severity on tomato caused by Fusarium spp.

In certain plant-fungus interactions, Fe is reported to have an important role during infection by promoting pathogen growth and enhancing tissue decay. Hendrix et al. (12) reported that growth of Phytophthora parasitica var. nicotianae was enhanced by minor elements such as $\mathrm{Fe}^{3+}$ when added to a synthetic glucose asparagine medium. The formation and infectivity of Phytophthora zoospores on pine cotyledons was enhanced by $\mathrm{Fe}$ and $\mathrm{Mg}$ (11). Fe also has been reported to promote brown-rot decay of treated wood (18). When Fe was added to malt-agar medium, decay of pine by inoculum of Serpula lacrymans grown on the

Corresponding author: Z. K. Punja; E-mail address: punja@ sfu.ca

DOI: 10.1094/PHYTO-96-1179

(c) 2006 The American Phytopathological Society
Fe-amended medium was enhanced (20). Decaying tissues of hardwood trees were shown to accumulate higher mineral levels (including $\mathrm{Fe}$ ) compared with healthy wood $(29,30)$. Under laboratory conditions, a correlation between a range of minerals, including $\mathrm{Fe}$, and mycelial growth of fungi associated with wood discoloration in maple, birch, beech, and ash was observed. Shigo (31) suggested that these fungi, which were wound invaders, had adapted to the high concentrations of minerals that were sequestered in discolored and decayed tissues.

Cylindrocarpon root rot of American ginseng (Panax quinquefolius L.), caused by Cylindrocarpon destructans (Zins) Scholten, is an important disease in ginseng-growing regions of Canada $(21,24,25)$. The disease is enhanced by wounding, and severity is greater at soil pH 5.0 than 7.0 (23). Infection of the roots can result in complete decay; hence, the name "disappearing root rot" frequently is used to describe this disease. The role of micronutrients, in particular $\mathrm{Fe}$, on disease development has not been studied previously. The objectives of this study were to determine whether Fe could enhance Cylindrocarpon root rot development through its effect on pathogen growth and infection as well by promoting tissue decay.

\section{MATERIALS AND METHODS}

Effect of Fe on Cylindrocarpon root rot. Hydroponic study. A hydroponic method for maintaining ginseng roots was utilized to determine the effect of $\mathrm{Fe}$ on disease initiation and to visualize the progress of infection. Two-year-old ginseng plants were dug 
from a ginseng garden in Kamloops, BC, Canada. Plants with surrounding rhizosphere soil were transferred to $15-\mathrm{cm}$ pots, which were covered with polyethylene bags and brought to the laboratory within $24 \mathrm{~h}$. The roots were kept under running tap water to remove any loosely attached microbes on the root surface and examined for blemishes, and healthy roots were inserted through precut holes in a Styrofoam block and suspended into a container of Hoagland's solution (HS) that was modified by adding FeNaEDTA (Sigma-Aldrich, St. Louis) to achieve concentrations of $56 \mu \mathrm{g} / \mathrm{ml}$ (normal Hoagland's) or $112 \mu \mathrm{g} / \mathrm{ml}$ (twice Hoagland's) and compared with Hoagland's with no added Fe. A highly aggressive isolate of $C$. destructans obtained from ginseng roots was grown on potato ginseng agar (23) and spores were added to the nutrient solution to achieve $5 \times 10^{5}$ spores $/ \mathrm{ml}$ in each container (Sigma plant cell culture vessel, Phytacon; Sigma-Aldrich). The solution was aerated through a direct airflow line on a lab bench and incubated under low intensity light $\left(40 \mu \mathrm{mols}^{-1} \mathrm{~m}^{-2}\right)$. Roots were rated for disease severity at 3-day intervals after inoculation using a 1-to- 6 scale, where $1=$ no visible lesions, $2=$ brown lesions up to $0.9 \mathrm{~mm}$ in diameter, $3=$ dark brown lesions of 1 to $4.0 \mathrm{~mm}, 4$ = black lesions of 4 to $7.0 \mathrm{~mm}, 5=$ black lesions $>7.0 \mathrm{~mm}$ coalesced with each other, and $6=$ fully rotten roots. A disease severity index (DSI) then was calculated using the formula DSI $=\left(\left[\mathrm{X}_{1} \times 1\right]+\left[\mathrm{X}_{2} \times 2\right]+\left[\mathrm{X}_{3} \times 3\right]+\left[\mathrm{X}_{4} \times 4\right]+\right.$ $\left.\left[X_{5} \times 5\right]+\left[X_{6} \times 6\right]\right) /\left(X_{1}+X_{2}+X_{3}+X_{4}+X_{5}+X_{6}\right)$, where $X_{1}, X_{2}$, $\mathrm{X}_{3}, \mathrm{X}_{4}, \mathrm{X}_{5}$, and $\mathrm{X}_{6}$ are the numbers of plants with rotting severity of $1,2,3,4,5$, and 6 , respectively. There were six replicate roots in each container and the experiment was conducted three times. Data from disease severity in all three experiments were pooled together after testing the homogeneity of variance $(P \leq 0.05)$; means of treatments were compared by Fisher's protected least significant difference (LSD) at the 5\% level. Statistical analysis was performed with the Statistical Analysis System (version 8; SAS Institute Inc., Cary, NC).

Field study. To determine the effect of Fe on root rot severity under field conditions, a 5-by-1-m area in each of four replicate beds was selected in a 3-year-old ginseng garden located in Kamloops, BC, and Heffley Creek, BC during the 2003 and 2004 growing seasons, respectively. Both fields had a prior history of Cylindrocarpon root rot and the pathogen was recovered from visibly diseased plants in certain areas of the field. Groups of 30 visibly healthy plants in each replicate plot were selected for the following treatments: (i) wounding of roots at the crown by piercing them 8 to 10 times with a fine needle (an insect mounting pin) to approximately $1.0 \mathrm{~mm}$ in depth by $0.25 \mathrm{~mm}$ in diameter, (ii) wounding of roots followed by drenching with Fe solution $(0.05 \%$ FeNaEDTA), and (iii) control (unwounded, drenched with water or Fe). The straw mulch and soil at the crown of each root was carefully removed to expose the roots and facilitate application of treatments and then replaced. The roots in each plot were dug up after 30 days, washed, and rated for disease severity using the DSI scale described previously.

In a separate experiment conducted in a 3-year-old ginseng garden in Kamloops, BC during the 2002 and 2003 growing seasons which had no history of Cylindrocarpon root rot, foliar applications of FeNaEDTA $(0.05 \%)$ were made during the first week of June, July, and August. The experimental plots, each measuring $1.22 \mathrm{~m}^{2}$, contained $\approx 100$ plants which were sprayed with a hand-held sprayer to run-off. Corresponding control plots were sprayed with water. During September, the ginseng roots were harvested, transported to the laboratory, and washed. Fetreated and control roots were inoculated with $0.5-\mathrm{cm}^{2}$ mycelial plugs (three plugs per root) taken from a 14-day-old culture of a highly aggressive isolate of $C$. destructans and incubated in a sealed plastic container layered with moist paper towels. Lesion diameter was measured in two orthogonal directions from four replicate roots after 3 weeks. The experiment was conducted three times, once in 2002 and twice in 2003. Data from the experiments in different years were pooled after testing the homogeneity of variance $(P \leq 0.05)$. Data for the means of treatments were compared using Fisher's protected LSD test at the 5\% level using Statistical Analysis System (version 8.0; SAS Institute).

Measurement of nutrient levels and phenolic compounds. Epidermal and cortical tissues from Fe-treated and control roots, as well as from Cylindrocarpon-infected and healthy regions on the same root, were removed with a sharp scalpel to make a composite sample for each treatment. For nutrient analysis, dried tissue $(0.2 \mathrm{~g})$ was digested with $40 \%$ (vol/vol) hydrofluoric acid mixed with nitric acid. The digested sample was made up to $100 \mathrm{ml}$ with $1 \%$ nitric acid. Aliquots of this solution were mixed with an internal standard and analyzed by inductively coupled plasma atomic emission spectrometry (ICP-AES) as previously described by Dahlquist and Knoll (8) with slight modifications. Samples were compared with a calibration curve constructed using multi-element standards.

Tissues from Cylindrocarpon-infected and healthy areas were also analyzed for specific phenolic compounds. For phenolic extraction, an equal amount ( $2 \mathrm{~g})$ of tissues was weighed, transferred to a mortar, frozen in liquid $\mathrm{N}_{2}$, and ground with a pestle. Ground tissues were transferred to a Falcon tube with $20 \mathrm{ml}$ of $80 \%$ methanol. The mixture was stirred at $37^{\circ} \mathrm{C}$ in a water bath for $30 \mathrm{~min}$, followed by centrifugation at $8,000 \times g$ for $10 \mathrm{~min}$. The supernatant was transferred to a new tube and evaporated to dryness using a rotary evaporator. The dry residue then was dissolved in $5 \mathrm{ml}$ of solvent containing methanol, formic acid, and water (70:8:22), which constituted the mobile phase for highperformance liquid chromatography (HPLC). The concentrated extract was centrifuged at $12,000 \times g$ for $10 \mathrm{~min}$ and filtered through a $0.2-\mu \mathrm{m}$ hydrophilic Durapore membrane filter (Millipore Corp., Bedford, MA). The extract $(50 \mu \mathrm{l})$ was injected through an Atlantis $\mathrm{dC}_{18}$ column in an LC-module 1 Waters HPLC machine (Mildford, MS) at a flow rate of $1.2 \mathrm{ml} / \mathrm{min}$ and the absorbance was recorded at $280 \mathrm{~nm}$ over a $24-$ min retention time. Identification of compounds was done by comparing (overlaying) the peaks at specific retention times with chromatograms of authentic purified compounds used as external standards (Sigma-Aldrich).

Phenolic-Fe binding assay. Ginseng callus cultures were initiated from root tissues as described by Tirajoh et al. (34). Briefly, surface-sterilized root segments were placed on Murashige and Skoog (MS) medium (19) containing a full complement of salts and vitamins and the growth regulators naphthaleneacetic acid (NAA) and 2,4-dichlorophenoxyacetic acid (2,4-D) at $10.0 \mu \mathrm{M}$ and $9.0 \mu \mathrm{m}$, respectively. Developing calli were subcultured to fresh medium every 6 to 8 weeks. To initiate suspension cultures, the method described by Punja et al. (22) was used. Cell masses were placed in $25 \mathrm{ml}$ of MS medium in a 125-ml Erlenmeyer flask and shaken at $125 \mathrm{rpm}$. The growth regulators subsequently were reduced to $2.5 \mu \mathrm{M}$ NAA and $2.0 \mu \mathrm{M}$ 2,4-D. Cell masses proliferated under these conditions and the spent medium was replaced with fresh medium every 2 weeks. Cell masses were collected by filtration through sterile cheesecloth. Calli ( $2 \mathrm{~g})$ from the MS medium were transferred to each of 27 flasks containing $100 \mathrm{ml}$ of liquid MS and the flasks were incubated on a shaker at $75 \mathrm{rpm}$ for 1 week at ambient room temperature $\left(21 \pm 2{ }^{\circ} \mathrm{C}\right)$. The calli then were transferred to a similar flask containing the same amount of MS amended with either Fe (as FeNaEDTA; SigmaAldrich) at 0,56 , or $112 \mu \mathrm{g} / \mathrm{ml}$. Each Fe concentration had nine flasks, of which three were kept as a control without any other treatment. Three flasks received $0.5 \%$ chitosan (Apollo Chitosan, Burnaby, BC, Canada) and the remainder were sonicated with a Virsonic 60 sonicator (The Virtis Company, Inc., NY) at $20 \mathrm{Hertz}$ for $30 \mathrm{~s}$. All flasks were incubated for another 2 weeks under the same conditions as described above, after which time the MS medium was poured off and the calli were washed twice with $100 \mathrm{ml}$ of sterile deionized water. Calli from each treatment and 
the controls were analyzed for Fe by ICP-AES as described above.

Translocation of $\mathbf{F e}\left({ }^{\mathbf{5 9}} \mathbf{F e}\right)$ from leaves. Radioactive $\mathrm{Fe}\left({ }^{59} \mathrm{FeCl}_{3}\right)$ with a specific activity of $2.94 \mathrm{MBq}$ in $0.5 \mathrm{M} \mathrm{HCl}$ (Amersham Bioscience, GE Healthcare, Canada) was used as an iron tracer. After dilution, an excess of EDTA was added to a final concentration of $0.1 \mathrm{mM}$ Fe-EDTA. Two-year-old ginseng plants were dug from a ginseng garden in Kamloops, BC. Plants with surrounding rhizosphere soil were transferred to 15 -cm-diameter pots which were covered with polyethylene bags and brought to the laboratory within $24 \mathrm{~h}$. Soil from around the crowns was carefully removed to make wounds with a sharp needle. Radioactive $\mathrm{Fe}\left({ }^{59} \mathrm{Fe}\right)$ was applied to one group of plants immediately after wounding and to another group 1 week after wounding. The ${ }^{59} \mathrm{Fe}$ solution was applied as $10-\mu \mathrm{l}$ droplets (three drops on each leaflet) on three leaflets per plant. Each droplet covered an area of 70 to $100 \mathrm{~mm}^{2}$. In order to facilitate ${ }^{59} \mathrm{Fe}$ uptake, the upper epidermis was injured gently by scratching with a scalpel. One week after ${ }^{59} \mathrm{Fe}$ application, the roots were harvested from the pots. Using a sharp razor, cross-sections were made through the crown, middle, and tip region $(2.5 \mathrm{~cm}$ from the root tip). The root sections were exposed to a Phosphor-Imaging screen overnight, followed by scanning in a Phosphor-Imager (Typhoon 9410; Molecular Dynamics, Amersham Biosciences, Piscataway, NJ). An image analysis was performed with the digitalized autoradiograph picture (Image Quant 5.2) to produce semiquantitative measures of radioactivity per area or activity profiles. These were compared with a calibrated standard composed of four different levels of ${ }^{59} \mathrm{Fe}$ activity and exposed simultaneously. Values were obtained by comparing the relative amount of shaded area within the standard with that of the root sample. Cross-sectional transects through scanned images of the root samples also were analyzed on a Macintosh computer using the public domain NIH Image program (developed at the U.S. National Institutes of Health [NIH]; provided online by $\mathrm{NIH}$ ) to create graphs. To obtain quantitative results, tissue pieces $\approx 4 \mathrm{~mm}^{2}$ in size were excised from the region of the secondary phloem taken from the crown, middle, and tip regions of roots and weighed. Tissues were ground in liquid $\mathrm{N}_{2}$ and solubilized in organic base (Soluene 350; Sigma-Aldrich). The solution then was added to a scintillation cocktail (Amersham BioScience) and ${ }^{59} \mathrm{Fe}$ activity was determined using a scintillation counter (LS 6500; Beckman Counter, CA). The analyses were conducted using three replicate samples.

Effect of Fe on fungal growth. A glucose-yeast extract broth (29) containing $5 \mathrm{~g}$ of glucose and $1 \mathrm{~g}$ of yeast extract in 1 liter of water was used as the basal medium. FeNaEDTA (Sigma-Aldrich) was added to achieve an Fe concentration of 0,56 , and $112 \mu \mathrm{g} / \mathrm{ml}$. Flasks containing $100 \mathrm{ml}$ of medium were inoculated with a $0.5-\mathrm{cm}^{2}$ mycelial plug from a 14-day-old colony of a highly aggressive isolate of $\mathrm{C}$. destructans and incubated on a rotary shaker $(150 \mathrm{rpm})$ for 2 weeks. The mycelial mass from four replicate flasks was filtered, dried at $40^{\circ} \mathrm{C}$ for $72 \mathrm{~h}$, and weighed. The experiment was conducted twice. Data from both experiments were pooled after testing the homogeneity of variance and analyzed by the analysis of variance (ANOVA) of the Statistical Analysis System (version 8.0; SAS Institute).

Effect of $\mathrm{Fe}$ on spore production and germination. FeNaEDTA was added to potato dextrose agar (PDA) (full strength; BDH, Darmstadt, Germany) to achieve an Fe concentration of 0,56 , and $112 \mu \mathrm{g} / \mathrm{ml}$, assuming release of Fe into the medium from FeNaEDTA over time, and $25 \mathrm{ml}$ was poured into each petri dish. Petri dishes were inoculated with a $0.5-\mathrm{cm}^{2}$ mycelial plug from a 14-day-old PDA colony of $C$. destructans followed by 2 weeks of incubation at ambient room temperature $\left(21 \pm 2^{\circ} \mathrm{C}\right)$ under fluorescent lights $(16 \mathrm{~h} /$ day $)$. Water $(15 \mathrm{ml})$ was added to each colony, followed by two washings with $10 \mathrm{ml}$ of water each, and spores were counted in a hemacytometer. For germ tube growth measurements, spores were obtained from colonies grown on potato ginseng agar (23) by adding either water or HS with $\mathrm{Fe}$ at 56 or $112 \mu \mathrm{g} / \mathrm{ml}$ and diluted to achieve a concentration of 15 to 20 spores/ $\mu \mathrm{l}$. Drops of spore suspension $(5 \mu \mathrm{l})$ were placed on glass slides and germinating spores were counted after incubating overnight inside petri dishes containing water agar. Germ tube lengths of 100 germinated spores were measured using a micrometer after 8 and $16 \mathrm{~h}$ of incubation. The extent of secondary branching of germ tubes also was recorded. The experiment was conducted twice with three replications and the data averaged.

Effect of Fe on extracellular enzyme production by $C$. destructans. The method described by Rahman and Punja (23) was used to measure pectinase and polyphenoloxidase activity with slight modification. In addition to using all of the recommended salts and substrates, the broth was further modified by adding $\mathrm{Fe}$ at 0,56 , or $112 \mu \mathrm{g} / \mathrm{ml}$. In the case of pectinase activity, the assay medium also was amended with different concentrations of $\mathrm{Fe}(0$, 56 , and $112 \mu \mathrm{g} / \mathrm{ml})$. The remaining assay procedures were as described by Rahman and Punja (23).

Siderophore formation. Chrome-azurol S (CAS) medium was prepared following the method described by Schwyn and Neilands (28). Petri dishes containing $25 \mathrm{ml}$ of CAS medium were inoculated with agar blocks containing mycelium from a 14-day-old culture of $C$. destructans, arranged in a triangular shape, and incubated at ambient room temperature $\left(21 \pm 2^{\circ} \mathrm{C}\right)$ for a week. Clearing zones and a change in color of the medium from bluish-green to orange at the colony margin indicated the putative production of siderophore (28).

\section{RESULTS}

Effect of Fe on Cylindrocarpon root rot. Hydroponic study. The addition of $\mathrm{Fe}$ at $56 \mu \mathrm{g} / \mathrm{ml}$ significantly enhanced disease initiation and severity compared with no $\mathrm{Fe}$, and $\mathrm{Fe}$ at $112 \mu \mathrm{g} / \mathrm{ml}$ supported more disease than at $56 \mu \mathrm{g} / \mathrm{ml}$ (Fig. 1A). With no Fe, necrotic lesions appeared on ginseng roots at 12 days after inoculation (DAI) compared with 9 and 6 DAI for Fe at 56 and $112 \mu \mathrm{g} / \mathrm{ml}$, respectively (Fig. 2). Disease development also was more rapid with $\mathrm{Fe}$ at $112 \mu \mathrm{g} / \mathrm{ml}$ compared with $\mathrm{Fe}$ at 0 and $56 \mu \mathrm{g} / \mathrm{ml}$, which contributed to a significantly higher disease severity index (DSI) at higher Fe concentrations (Fig. 2). Lesion development with $\mathrm{Fe}$ at $112 \mu \mathrm{g} / \mathrm{ml}$ resulted in complete loss of feeder roots and, eventually, the entire root rotted (Fig. 1A). At this stage, some of the roots were found to be colonized also by Fusarium solani, presumably from low levels of residual inoculum on the field-grown roots.

Field study. Extensive rotting in the crown region was observed on roots that received a combination of wounding and Fe treatment compared with wounding or Fe alone (Fig. 1B to D; Table 1). The wounded plus Fe-treated plants also had significantly higher plant mortality compared with wounded roots (Table 1). Wounded roots showed minor browning as well as wound-healing responses that included callus formation at wound sites (Fig. 1C). C. destructans was isolated from diseased tissues and isolates were found to comprise both highly and weakly aggressive strains (23). In vitro inoculations with $C$. destructans showed larger lesion development on Fe-treated roots compared with the control (Fig. 1E), with a mean lesion diameter on Fe-treated roots of $1.4 \mathrm{~cm}$ compared with $0.6 \mathrm{~cm}$ on the control roots. This difference was observed in both years of the experiment.

Measurement of nutrient levels and phenolic compounds. The ICP-AES analysis of healthy and $C$. destructans-infected root tissues showed significant differences in a number of elements, especially $\mathrm{Fe}$ and $\mathrm{Mn}$ (Table 2). This trend was observed in replicate root samples and when the tissue analysis was repeated using samples from naturally infected as well as artificially inoculated roots. Nutrient analysis of foliar-applied Fe-treated plants showed significantly higher Fe levels in roots compared with the 

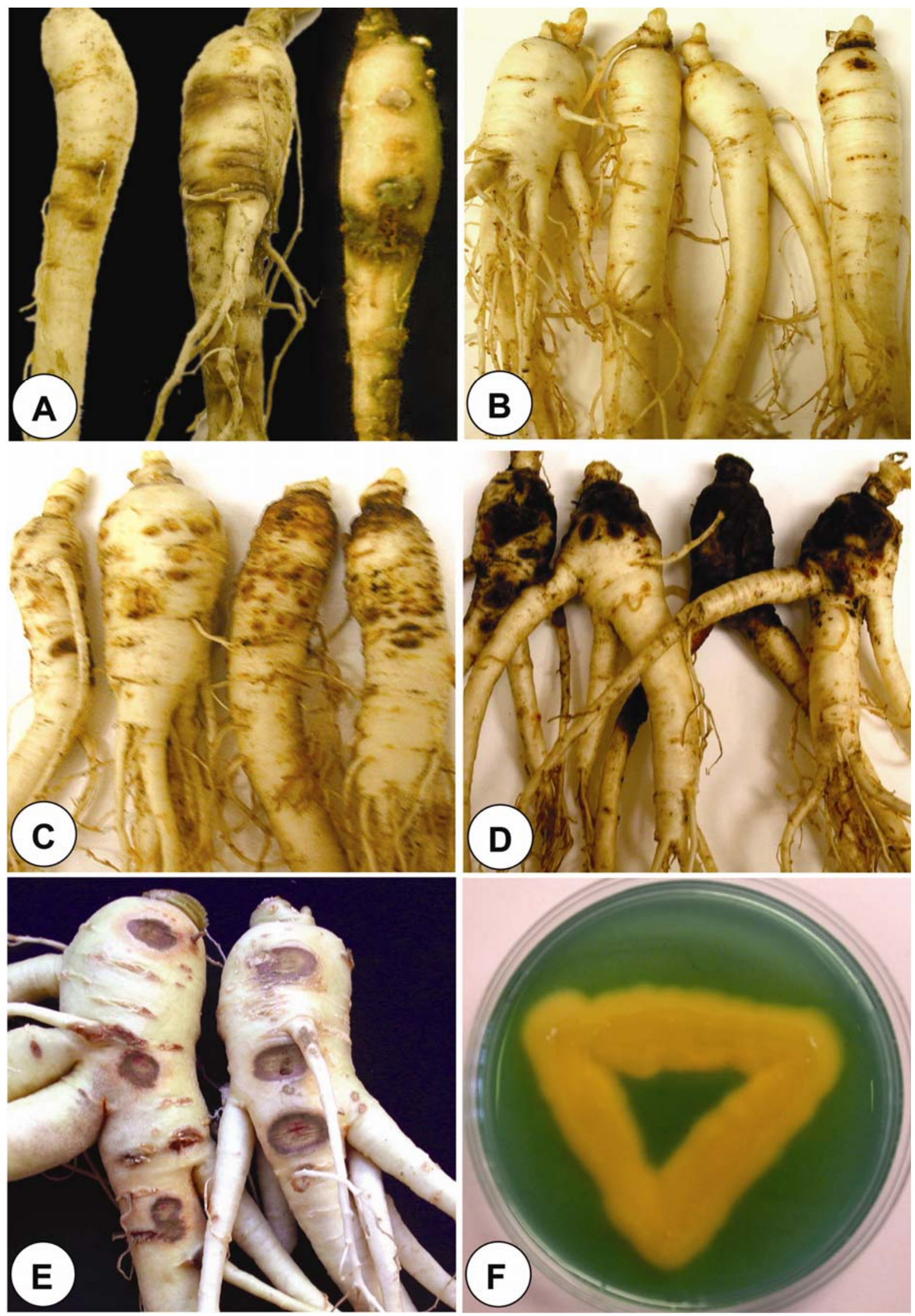

Fig. 1. Effect of iron (Fe) on root rot of ginseng and on Cylindrocarpon destructans growth. A, Lesion development on hydroponically maintained roots with different Fe levels and inoculated with $C$. destructans spores: left $=$ zero Fe, middle $=56 \mu \mathrm{g} / \mathrm{ml} \mathrm{Fe}$, and right $=112 \mu \mathrm{g} / \mathrm{ml} \mathrm{Fe}$. B, Control roots from the field study. $\mathbf{C}$, Wounded roots with minor browning and wound healing response. D, Roots with extensive rotting due to $C$. destructans at the crown as a result of wounding followed by Fe drench. E, Roots showing lesions following inoculation with $C$. destructans mycelial plugs from a 14-day-old culture; left $=$ control and right $=$ foliar Fe treated. F, Clearing zone around $C$. destructans agar blocks arranged in a triangular pattern on chrome-azurol $\mathrm{S}$ medium indicating removal of Fe through production of siderophore and a change in color from green to orange. 
control (Table 3). The levels of all other nutrients in the Fe-treated and control roots were similar.

Total phenolic content in tissues infected with $C$. destructans was enhanced threefold compared with healthy tissues on the same root. The phenolic compounds which were significantly elevated in diseased tissues were identified by HPLC as protocatechuic acid, o-coumaric acid, phloridzin, caffeic acid, p-coumaric acid, benzoic acid, 3,4,5 tri methyl benzoic acid, cinnamic acid, and quercetin (Table 4). In addition, several phenolic compounds (ferulic acid and some unidentified peaks) were present in diseased tissues that were absent in healthy tissues.

Phenolic-Fe binding assays. Ginseng calli grown on MS medium containing elevated levels of $\mathrm{Fe}$ accumulated more $\mathrm{Fe}$ in the tissues (Fig. 3) and treatment with chitosan significantly $(P<$ 0.0001 ) enhanced $\mathrm{Fe}$ accumulation under the same growth conditions. Sonicated calli did not enhance Fe levels compared with the untreated control.

Translocation of $\mathbf{F e}\left({ }^{59} \mathbf{F e}\right)$ from leaves. Iron was detected in all roots when ${ }^{59} \mathrm{Fe}$ was applied to leaves. Image analysis showed that most of the radioactive $\mathrm{Fe}$ was translocated through the secondary phloem with lateral movement to epidermal tissues and especially to wounded areas (Fig. 4). There was no difference in radioactivity around wounds made just prior to ${ }^{59} \mathrm{Fe}$ application or a week earlier. Higher radioactivity was detected in wounded compared with unwounded areas on the root. Within a week, radioactive $\mathrm{Fe}$ was present in the crown region to the proximity of root tips over a gradient of decreasing concentration. Scintillation counts from a sample of root tissue $\left(4 \mathrm{~mm}^{2}\right.$ by $0.5 \mathrm{~mm}$ thick) from the crown, middle, and root-tip regions indicated levels of $2,500,1,000$, and $650 \mathrm{cpm}$ of radioactivity ( $\beta$ emission), respectively. Graphs created from cross-sectional transects of scanned images showed taller peaks in the secondary phloem and cortical zone where wound-induced phenolic accumulation took place near the crown. Primary vascular tissues in and around the stele, including the secondary xylem, did not show any accumulation of radioactivity.

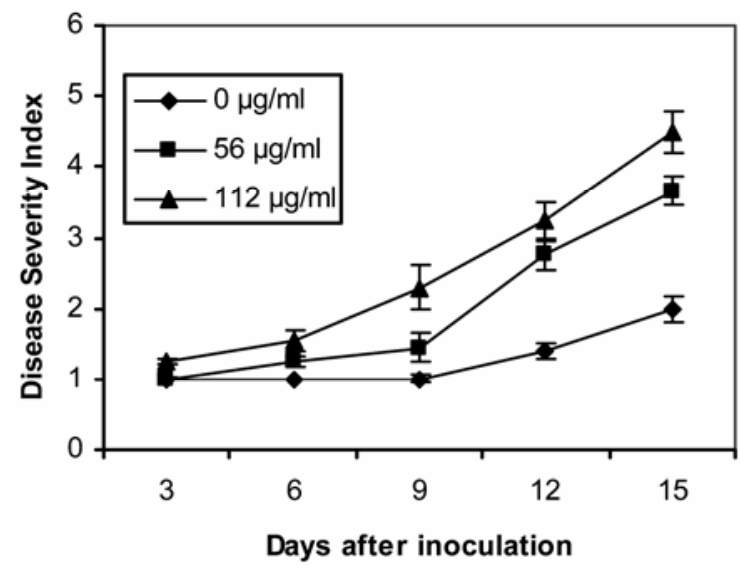

Fig. 2. Progression of Cylindrocarpon destructans root rot on hydroponically maintained ginseng roots with iron at 0,56 , and $112 \mu \mathrm{g} / \mathrm{ml}$. Vertical bars represent the standard errors of means from data pooled from three experiments $(n=27)$.
Effect of Fe on fungal growth. Mycelial mass produced in glucose-yeast broth was significantly higher $(P<0.001)$ with $\mathrm{Fe}$ at both 56 and $112 \mu \mathrm{g} / \mathrm{ml}$ in the medium compared with $0 \mathrm{Fe}$. The stimulatory effect of $\mathrm{Fe}$ on mycelial mass production was in the order of $112>56>0.0$ (Fig. 5).

Effect of Fe on spore production, germ tube length, and secondary branching of hyphae. Fe significantly enhanced

TABLE 2. Micronutrient levels in epidermal tissues of healthy and C. destructans-infected ginseng roots

\begin{tabular}{lcc}
\hline & \multicolumn{2}{c}{ Concentration $(\mu \mathrm{g} / \mathrm{g})^{\mathrm{z}}$} \\
\cline { 2 - 3 } Micronutrient & Healthy & Diseased \\
\hline Boron & 6.9 & 9.3 \\
Copper & 4.2 & 5.3 \\
Iron & 38.4 & 183 \\
Manganese & 13.8 & 34.5 \\
Molybdenum & $<0.5$ & $>0.5$ \\
Zinc & 17.6 & 16.3 \\
\hline
\end{tabular}

${ }^{\mathrm{z}}$ Data are the average from three replicate samples.

TABLE 3. Nutrient levels in the epidermal tissues of iron (Fe)-treated and untreated ginseng roots

\begin{tabular}{lcc}
\hline & \multicolumn{2}{c}{ Concentration $(\mu \mathrm{g} / \mathrm{g})^{\mathrm{z}}$} \\
\cline { 2 - 3 } Element & Fe-treated & Control \\
\hline Calcium & 2,700 & 2,700 \\
Phosphorus & 1,300 & 1,500 \\
Potassium & 9,400 & 8,300 \\
Magnesium & 1,200 & 1,400 \\
Sodium & 200 & 200 \\
Sulfur & 400 & 600 \\
Zinc & 13.9 & 10.8 \\
Boron & 10.3 & 11.0 \\
Manganese & 11.0 & 10.5 \\
Fe & 100.0 & 52.4 \\
Molybdenum & $<0.6$ & $<0.6$ \\
\hline z Three Fe applications were made to foliage of 3-year-old ginseng plants in \\
2002 and 2003. Data are the average from six replicate samples (three \\
replicates in each year).
\end{tabular}

TABLE 4. Phenolic compounds in epidermal and cortical tissues of healthy and $C$. destructans-infected ginseng roots

\begin{tabular}{lcc}
\hline & \multicolumn{2}{c}{ Tissue levels $(\mu \mathrm{g} / \mathrm{g}$ fresh weight $)$} \\
\cline { 2 - 3 } Phenolic compounds $^{\mathrm{z}}$ & Healthy & Diseased \\
\hline Protocatechuic acid & 1.11 & 2.81 \\
O-Coumaric acid & 0.48 & 2.32 \\
Phloridzin & 2.31 & 12.24 \\
Caffeic acid & 0.45 & 2.40 \\
p-Coumaric acid & 0.47 & 2.57 \\
Benzoic acid & 0.27 & 1.59 \\
3,4,5 Tri methyl benzoic acid & 0.24 & 2.08 \\
Ferulic acid & 0.09 & 0.86 \\
Cinnamic acid & 0.18 & 2.50 \\
Quercetin & 0.24 & 6.12 \\
\hline
\end{tabular}

${ }^{\mathrm{z}}$ Phenolic compounds were identified by high-performance liquid chromatography. The data represent the mean of three different analyses.

TABLE 1. Effect of iron (Fe) treatment and wounding on Cylindrocarpon root rot incidence and severity on ginseng roots ${ }^{\mathrm{z}}$

\begin{tabular}{|c|c|c|c|c|c|}
\hline \multirow[b]{2}{*}{ Treatment } & \multicolumn{3}{|c|}{ Number of } & \multirow[b]{2}{*}{ Rotted roots (\%) } & \multirow[b]{2}{*}{ Disease severity index } \\
\hline & Treated roots & Rotted roots & Roots with lesions & & \\
\hline Wounding & 30 & 6 & 8 & $46.67 \mathrm{~b}$ & $2.60 \mathrm{~b}$ \\
\hline Wounding $+\mathrm{Fe}(56 \mu \mathrm{g} / \mathrm{ml})$ & 30 & 8 & 15 & $76.67 \mathrm{a}$ & $4.33 \mathrm{a}$ \\
\hline Control & 30 & 4 & 3 & $23.33 \mathrm{c}$ & $1.77 \mathrm{c}$ \\
\hline
\end{tabular}

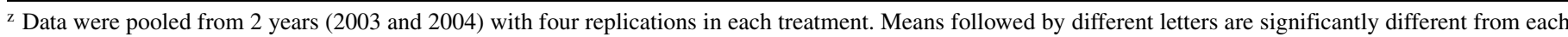
other according to Fisher's protected least significant difference test. Control plants received either water or Fe $(0.05 \%)$. 
sporulation in a relatively low-spore-producing isolate of $C$. destructans on PDA. After 2 weeks of incubation, colonies on PDA without $\mathrm{Fe}$ did not produce any spores, whereas colonies grown on PDA with $\mathrm{Fe}$ at 56 and $112 \mu \mathrm{g} / \mathrm{ml}$ produced 5 and $6 \times$

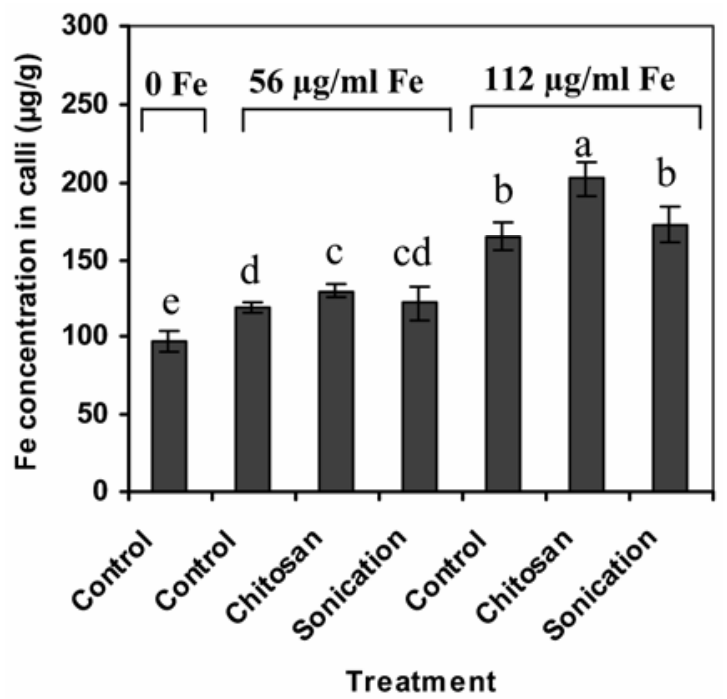

Fig. 3. Concentration of iron $(\mathrm{Fe})$ in ginseng calli treated with two different $\mathrm{Fe}$ levels and two phenolic inducers (chitosan and sonication). Data are the means of three replicates. Bars followed by a different letter are significantly different according to Fisher's protected least significant difference test $(P \leq 0.05)$.
$10^{5}$ spores, respectively (Fig. 6). Germ tube length was significantly higher with $\mathrm{Fe}$ at 112 compared with $56 \mu \mathrm{g} / \mathrm{ml}$ after $16 \mathrm{~h}$ of incubation (Fig. 7B). Very few spores showed secondary branching after $8 \mathrm{~h}$, but $\mathrm{Fe}$ at 56 and $112 \mu \mathrm{g} / \mathrm{ml}$ promoted significantly higher secondary branching of germ tubes compared with $0 \mathrm{Fe}$ after $16 \mathrm{~h}$ (Table 5).

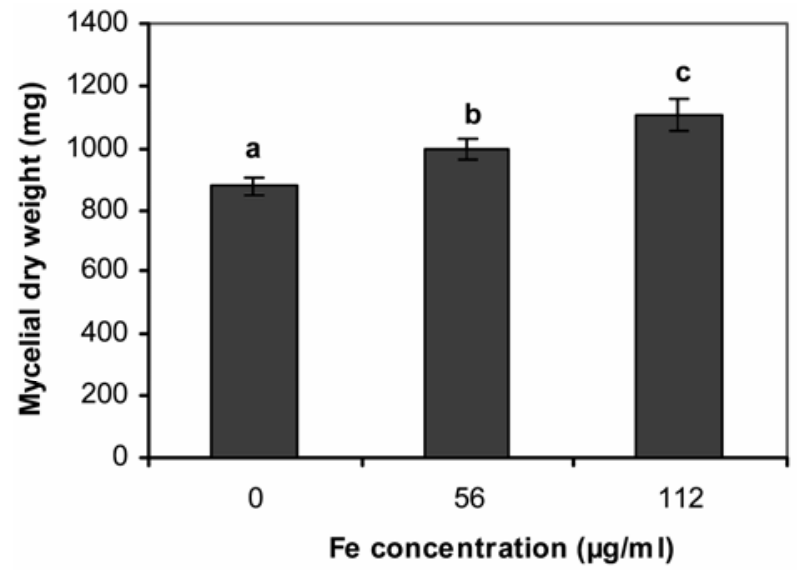

Fig. 5. Effect of iron $(\mathrm{Fe})$ on mycelial dry weight produced by Cylindrocarpon destructans. Bars followed by different letters are significantly different according to Fisher's protected least significant difference $(P \leq 0.05)$. Vertical bars represent the standard errors of means from three experiments, each having four replicate flasks $(n=12)$.
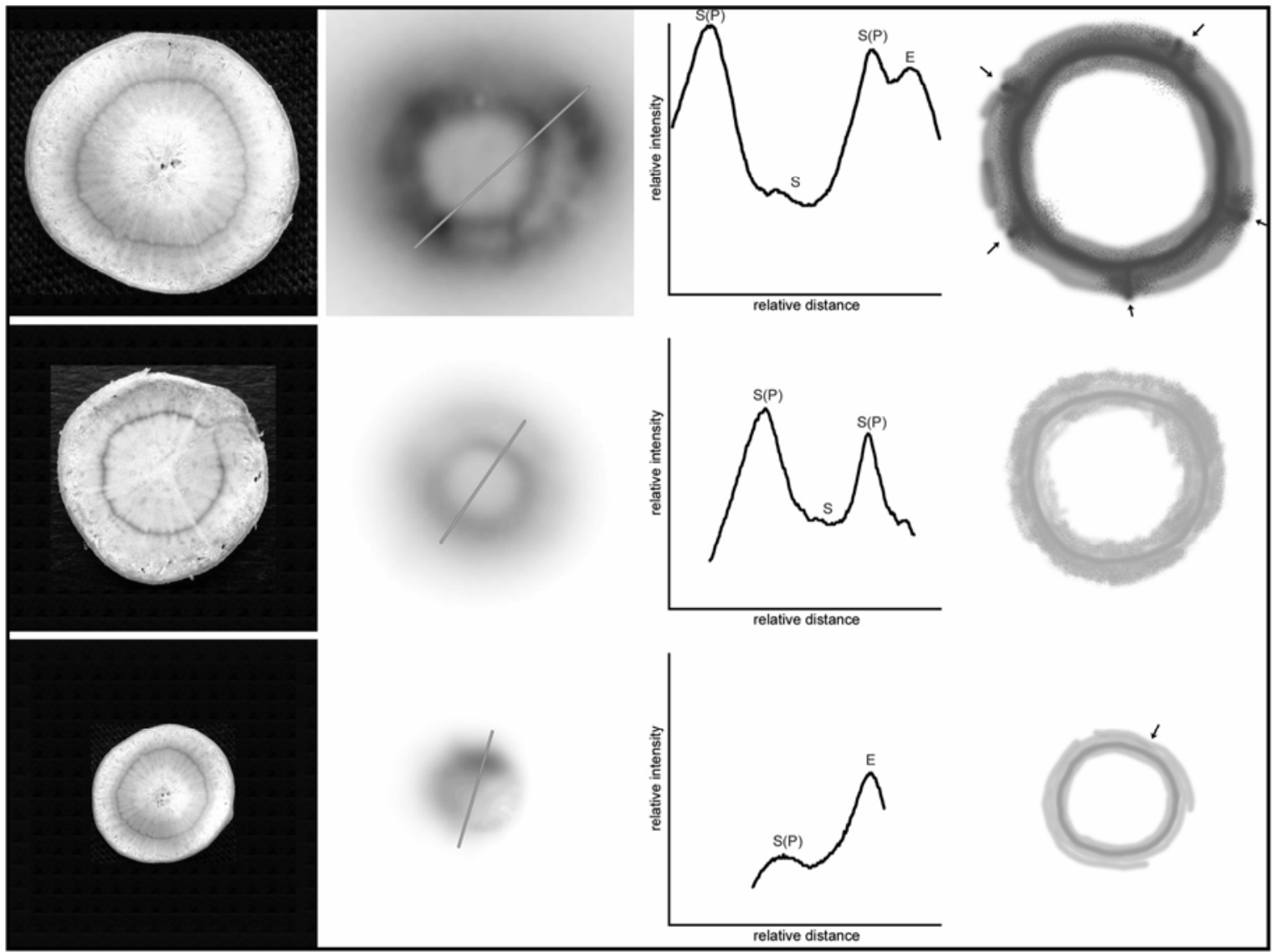

A

B

C

D

Fig. 4. Distribution of radioactive iron $\left({ }^{59} \mathrm{Fe}\right)$ in regions of ginseng roots 1 week after application to leaves. A, Thin sections of roots taken at the crown (top), middle, and root tip (bottom) regions. B, Phosphor-image scans of the thin sections from A; darkened zones correspond to radioactivity. C, Quantitative measures of radioactivity analyzed by National Institutes of Health image software. The different regions of the root are shown as $\mathrm{S}(\mathrm{P})$ for secondary phloem, $\mathrm{S}$ for stele, and $\mathrm{E}$ for epidermis. D, Schematic diagram of root areas seen in panel B to show radioactivity accumulation based on scintillation counts from different regions of the roots. Arrows indicate regions where wounds were made. 
Effect of Fe on extracellular enzyme production by $C$. destructans. Fe did not significantly increase pectinase activity; however, polyphenoloxidase (PPO) was significantly enhanced by adding Fe to the growth medium (Fig. 8).

Siderophore formation. $C$. destructans produced siderophores as evidenced by the clear zone on all sides of mycelial blocks (Fig. 1F), as well as a change in color of CAS medium from green to orange-yellow. This change is putative evidence for siderophore production (28).

\section{DISCUSSION}

The present study investigated the role of Fe on development of Cylindrocarpon root rot and potential mechanisms by which $\mathrm{Fe}$ could enhance disease incidence and severity. Greater mycelial mass in medium supplemented with Fe suggests a growth stimulation, consistent with the reports for fungi causing decay of woody tissues as well as $F$. graminearum, $F$. moniliforme, and Aspergillus flavus $(6,7)$ which were all stimulated by metal ions such as Fe.

Previously published results have indicated both an increase and decrease in plant diseases due to Fe application. For example, Fe reduced Verticillium wilt of eggplant and peanut (2) but increased Fusarium wilt of tomato (13) and cotton (32), and

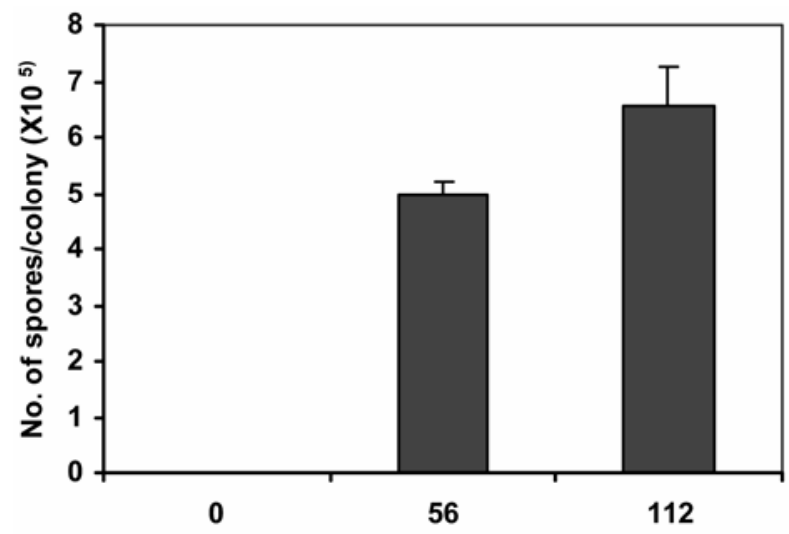

Fe concentration in the medium $(\mu \mathrm{g} / \mathrm{ml})$

Fig. 6. Effect of iron $(\mathrm{Fe})$ on sporulation of Cylindrocarpon destructions on potato-dextrose agar. Spores were enumerated after 14 days of incubation; vertical bars represent the standard errors of means from two experiments, each having three replicate flasks $(n=6)$. wheat rust (32). Hydroponic culture permitted observation of how $\mathrm{Fe}$ in the hydroponic solution could affect disease development at 3-day intervals on the same roots over the duration of the experiment. Fe significantly enhanced disease development and increased PPO activity of $C$. destructans. This enzyme may be a potential contributor to lesion development on ginseng roots. The dark-brown sunken lesions caused by $C$. destructans are likely the outcome of oxidation of host phenolic compounds by PPO. Ginseng roots produce a variety of phenolic compounds, including ginsenosides or ginseng saponins, which are the principal bioactive compounds (35). PPO production by fungi usually is in-

TABLE 5. Effect of iron (Fe) on germ tube length and secondary branching of mycelia from germinated spores of Cylindrocarpon destructans ${ }^{\mathrm{Z}}$

\begin{tabular}{lccccc}
\hline & \multicolumn{2}{c}{ Germ tube length $(\mathrm{mm})$} & & \multicolumn{2}{c}{ Secondary branching $(\%)$} \\
\cline { 2 - 3 } \cline { 5 - 6 } Fe level $(\mu \mathrm{g} / \mathrm{ml})$ & $8 \mathrm{~h}$ & $16 \mathrm{~h}$ & & $8 \mathrm{~h}$ & $16 \mathrm{~h}$ \\
\hline 0 & $0.09 \mathrm{a}$ & $0.2 \mathrm{a}$ & & $0 \mathrm{a}$ & $3.5 \mathrm{a}$ \\
56 & $0.17 \mathrm{~b}$ & $0.34 \mathrm{~b}$ & & $0 \mathrm{a}$ & $15 \mathrm{~b}$ \\
112 & $0.25 \mathrm{c}$ & $0.49 \mathrm{c}$ & & $<1 \mathrm{a}$ & $27 \mathrm{c}$ \\
\hline
\end{tabular}

${ }^{z}$ Treatments were applied in Hoagland's solution. Data are means of 100 germinated spores. Data in a single column followed by the same letter are not significantly different from each other according to Fisher's protected least significant difference test.

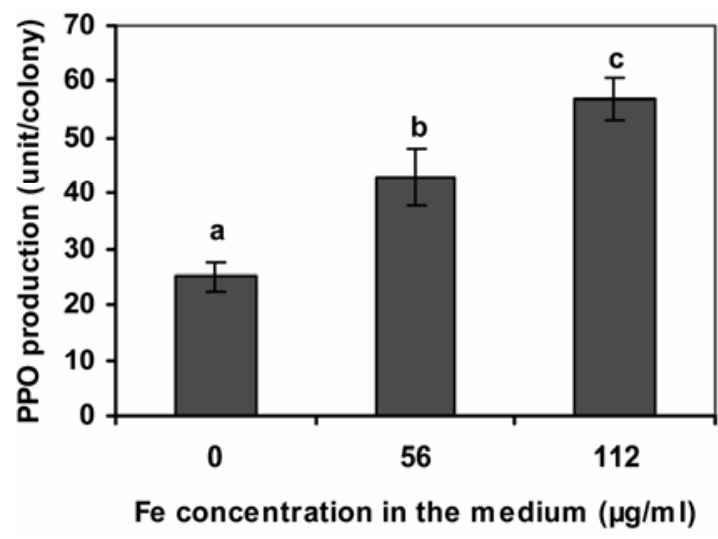

Fig. 8. Effect of iron $(\mathrm{Fe})$ on polyphenoloxidase (PPO) production by Cylindrocarpon destructans. Bars followed by different letters are significantly different according to Fisher's protected least significant difference $(P \leq 0.05)$. Vertical bars represent the standard errors of means from 3 experiments each having three replicate flasks $(n=9)$.
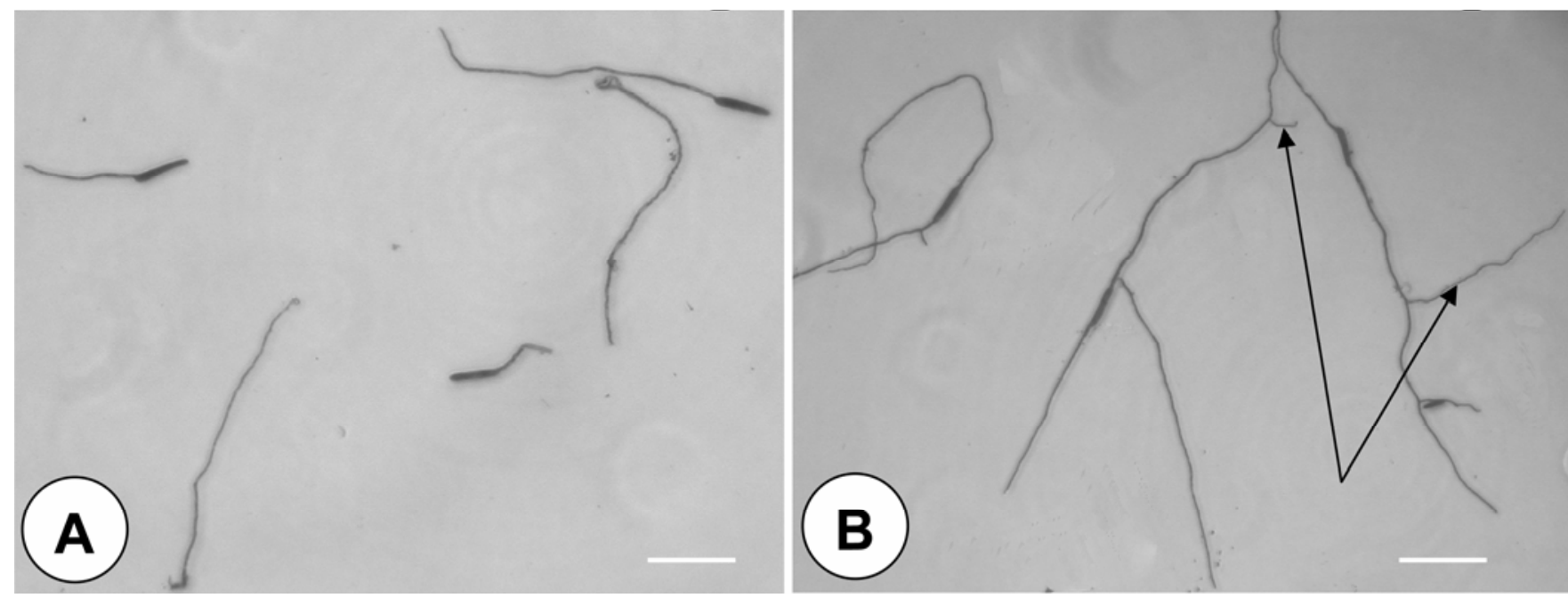

Fig. 7. Cylindrocarpon destructans spore germination and hyphal growth in Hoagland's solution with iron at A, 56 and $\mathbf{B}, 112 \mu \mathrm{g} / \mathrm{ml}$, scale bar $=25 \mu \mathrm{m}$. Arrows indicate secondary branching of germ tubes. 
duced by phenolic substances in the host plant or in artificial media, and helps the pathogen to degrade cell wall constituents or detoxify host quinones by polymerization (17). In a previous study, we reported that ginseng cells infected by $C$. destructans stained a bluish green with Toluidine blue $\mathrm{O}$, indicating the presence of host phenolic compounds in diseased tissues (23).

Excessive Fe concentrations (up to $336 \mu \mathrm{g} / \mathrm{ml}$ ) do not inhibit growth of $C$. destructans in vitro (data not shown), suggesting that $C$. destructans is tolerant of high Fe levels. Tissue Fe levels following three applications of FeNaEDTA were $\approx 100 \mu \mathrm{g} / \mathrm{g}$. Several brown and white-rot fungi produce low molecular weight metal-chelator agents or siderophores (10). These chelators reduce ferric Fe for fungal metabolic functions. However, part of the reduced $\mathrm{Fe}$ is released into the environment where it reacts with oxidants such as hydrogen peroxide to produce free radical species which, in turn, are active chemical oxidizers of both cellulosic and phenolic compounds (10). In Cylindrocarpon root rot of ginseng, formation of dark-brown necrotic lesions is indicative of the oxidation of phenolic compounds which likely involves Fe. Levels of $\mathrm{Fe}$ in diseased tissue were fourfold higher than in adjoining healthy tissues. Putative production of uncharacterized siderophores by $C$. destructans was suggested by the positive reaction on CAS medium. In this medium, the ternary complex CAS/hexadecyltrimethyl-ammonium bromide (HDTMA) is used as the indicator. When a high-affinity $\mathrm{Fe}$ (III) chelator removes $\mathrm{Fe}$ from the dye complex, its color changes from blue to orange (28), as was observed in this study. In Gloeophyllum trabeum brownrotted wood, $\mathrm{Xu}$ and Goodel (36) showed a significant role of Gt chelator (Fe-chelator produced by G. trabeum), iron, $\mathrm{H}_{2} \mathrm{O}_{2}$, and $\mathrm{pH}$ in cellulose degradation that enhanced the overall rotting capacity of this fungus.

Radioactive $\mathrm{Fe}\left({ }^{59} \mathrm{Fe}\right)$ translocated from ginseng leaves to roots accumulated at a higher level around wound sites where phenolic production was induced. Binding of $\mathrm{Fe}$ following phenolic induction was demonstrated in vitro by the greater Fe content in ginseng calli treated with phenolic inducers such as chitosan (3) in the presence of supplemental Fe. Polyphenols, especially tannins, chelate heavy metals, such as $\mathrm{Fe}$, and play a role as potential antioxidants (26). Phenolic compounds are involved with metal chelation in vitro and in vivo $(4,5,14,15)$. Aoba (1) suggested that tannin-rich plants such as tea, which are tolerant to excess Mn, are protected by the direct chelation of Mn by tannins and that typical brown spots on leaves exposed to excess $\mathrm{Mn}$ are the result of tannin oxidation. Cheng and Crisosto (5) demonstrated that elevated levels of the phenolic compounds caffeic acid, chlorogenic acid, and catechin chelated Fe to form a Fe polyphenol complex which led to tissue discoloration in peach and nectarine epidermal tissues. Increased Fe levels observed in necrotic ginseng tissues compared with adjoining healthy tissues appear to be due in part to chelation by enhanced levels of phenolic compounds. Phenolic compounds with a galloyl or $3^{\prime}, 4^{\prime}$ dihydroxy (catechol) group on flavanoid ring B are especially important in Fe-binding. These include tannic acid, gallic acid, quercetin, chlorogenic acid, caffeic acid, and others $(4,14)$. A number of these were detected at high concentrations in diseased ginseng tissues.

High Fe levels in necrotic ginseng tissues (as well as Mn) compared with adjacent healthy tissues point to the ability of these cations to remobilize within the root as an outcome of either host defense response or fungal sequestration in or around the infection site. Fe treatment did not influence Mn levels in roots. Like Fe, Mn has been shown to be involved in disease development of Gaeumanomyces graminis var. tritici on wheat roots, and Mn was oxidized by the pathogen within lesions by the production of laccases (33). Dimarco et al. (9) reported a significantly higher level of $\mathrm{Fe}$ in grape leaves with esca symptoms compared with asymptomatic leaves. In the present study, wounding of roots followed by $\mathrm{Fe}$ drenching significantly increased disease due to
C. destructans compared with Fe alone or wounding alone, suggesting an additive effect and, thus, enhanced susceptibility.

Our previous study indicated that low soil $\mathrm{pH}$ favors Cylindrocarpon root rot development (23). Because low $\mathrm{pH}$ supports higher Fe availability to the plant, Fe may be one of the factors which could enhance disease severity under acidic conditions. Thus, managing soil factors such as $\mathrm{pH}$ and Fe availability may prove to be partially effective in disease management. The practice of foliar $\mathrm{Fe}$ applications conducted by ginseng growers in soils with alkaline to neutral $\mathrm{pH}$ also should be avoided in fields with a history of Cylindrocarpon root rot.

\section{ACKNOWLEDGMENTS}

We thank The Natural Sciences and Engineering Research Council of Canada (Discovery Grants Program and Collaborative Research and Development Program), The Science Council of British Columbia, GREAT awards program, and The Associated Ginseng Growers of British Columbia, for their financial assistance; the Chai-Na-Ta Ginseng Corp. for their cooperation, use of their facilities, provision of plant materials, and financial support; E. R. Littley and A. Plant for advice; and N. Verma for preparing the figures.

\section{LITERATURE CITED}

1. Aoba, K. 1986. Excess manganese disorder in fruit trees. Jpn. Agric. Res. Q. 20:45-47.

2. Barash, I., Zion, R., Krikun, J., and Nachmias, A. 1988. Effect of Fe status on Verticillium wilt disease and on in vitro production of siderophores by Verticillium dahliae. J. Plant Nutr. 11:839-905.

3. Benhamou, N. 1996. Elicitor-induced plant defence pathways. Trends Plant Sci. 1:233-240.

4. Brune, M., Rossander, L., and Hallberg, L. 1989. Iron absorption and phenolic compounds: Importance of different phenolic structures. Eur. J. Clin. Nutr. 43:547-558.

5. Cheng, G. W., and Crisosto, C. H. 1997. Fe-polyphenol complex formation and skin discoloration in peaches and nectarines. J. Am. Soc. Hortic. Sci. 122:95-99.

6. Cuero, R. 2001. Regulation of mycotoxin formation and fungal growth by metal ions and fertilizer: effect on fungal gene expression. Pages 355-361 in: Mycotoxins and Phycotoxins in Perspective at the Turn of the Millennium. D. Koe, W. J. Koe, R. A. Samson, H. P. van-Egmond, J. Gilbert, and M. Sabioino, eds. Proc. 10th Int. IUPAC Symp. Mycotoxins and Phycotoxins, Guaruja, Brazil. Wageningen, The Netherlands.

7. Cuero, R. Ibraguen, H., and Mmbjjwe, G. 2000. Fungal cytotoxicity and toxigenicity induced by metal ions: Effect on humans and animals. Pages 765-767 in: Metal Ions in Biology and Medicine, vol. 6. J. A. Ceneteno, P. H. Collery, G. Vernet, R. B. Finkleman, H. Gibb, and J. Etienne, eds. Eurotext, John Libbey.

8. Dahlquist, R. L., and Knoll, J. W. 1978. Inductively coupled plasmaatomic emission spectrometry: Analysis of biological materials and soils for major, trace, and ultra-trace elements. Appl. Spectrosc. 32:1-29.

9. Dimarco, S., Osti, F., Mazzulo, O., and Cesari, A. 2001. How Fe could be involved in esca fungi development. Phytopathol. Mediterr. 40S:449452 .

10. Goodell, B., Jellison, J., Liu, J., Daniel, A., Paszczynski, F., Fekete, F., Krishanamurthy, S., Jun, L., and Xu, G. 1997. Low molecular weight chelators and phenolic compounds isolated from wood decay fungi and their role in the fungal biodegradation of wood. J. Biotechnol. 53:133162.

11. Haalsal, D. M., and Forrester, R. I. 1977. Effects of certain cations on the formation and infectivity of Phytophthora zoospores. 1. Effects of calcium, magnesium, potassium and iron ions. Can. J. Microbiol. 23:9941001.

12. Hendrix, J. W., Guttman, S.-M., and Wightman D. L. 1969. Cation and sterol effects on growth of Phytophthora parasitica var. nicotianae. Phytopathology 59:1620-1624.

13. Jones, J. P., and Woltz, S. S. 1970. Fusarium wilt (race 2) of tomato: Calcium, $\mathrm{pH}$ and micronutrient effects on disease development. Plant Dis. Rep. 53:276-279.

14. Khokhar, S., and Richard, K. O. A. 2003. Iron binding characteristics of phenolic compounds: Some tentative structure-activity relations. Food Chem. 81:133-140.

15. Lavid, N., Schwartz, A., Yarden, O., and Tel-Or, E. 2000. The involvement of polyphenols and peroxidase activities in heavy-metal accumulation by epidermal glands of the waterlily (Nymphaeceae). Planta 212:323331. 
16. Lemanceau, P., Alabouvette, C., and Couteaudier, Y. 1988. Studies on the disease suppressiveness of soils. XIV. Modification of the receptivity level of a suppressive and conducive soil to Fusarium wilt in response to the supply of iron or of glucose. Agronomie 8:155-162.

17. Mayer, A. M., and Harel, E. 1979. Polyphenoloxidases in plants. Phytochemistry 18:193-215.

18. Morris, P. I. 1992. Available Fe promotes brown rot of treated wood. Publication no. 1526 of the International Research Group on Wood Preservation, Stockholm, Sweden.

19. Murashige, T., and Skoog, F. A. 1962. Revised medium for rapid growth and bioassays with tobacco tissue cultures. Physiol. Plant 15:473-497.

20. Paajanen, L. M. 1993. Fe promotes decay capacity of Serpula lacrymans. Publication no. 10008 of the International Research Group on Wood Preservation, Stockholm, Sweden.

21. Punja, Z. K. 1997. Fungal pathogens of American ginseng (Panax quinquefolius L.) in British Columbia. Can. J. Plant Pathol. 19:301-306.

22. Punja, Z. K., Feeney, M., Schluter, T., and Tautorus, T. 2004. Multiplication and germination of somatic embryos of American ginseng derived from suspension cultures and biochemical and molecular analyses of plantlets. In Vitro Cell. Dev. Biol. Plant 40:329-338.

23. Rahman, M., and Punja, Z. K. 2005. Factors influencing development of root rot on ginseng caused by Cylindrocarpon destructans. Phytopathology 95:1381-1390.

24. Reeleder, R. D., and Brammal, R. A. 1994. Pathogenicity of Pythium species, Cylindrocarpon destructans, and Rhizoctonia solani to ginseng seedlings in Ontario. Can. J. Plant Pathol. 16:311-316.

25. Reeleder, R. D., Roy, R., and Capell, B. B. 1999. Seed and root rots of ginseng (Panax quinquefolius) caused by Cylindrocarpon destructans and Fusarium spp. J. Ginseng Res. 26:151-158.

26. Rice-Evans, C. A., Miller, N. J., and Paganga, G. 1996. Structure-antioxidant activity relationship of flavonoids and phenolic acids. Free Radic.
Biol. Med. 20:933-956.

27. Scher, F. M., and Baker, R. 1982. Effect of Pseudomonas putida and a synthetic Fe chelator on induction of soil suppressiveness to the Fusarium wilt pathogen. Phytopathology 72:1567-1573.

28. Schwyn, B., and Neilands, J. B. 1987. Universal chemical assay for the detection and determination of siderophores. Anal. Biochem. 160:4756.

29. Shigo, A. L. 1970. Growth of Polyporus glomeratus, Poria oblique, Fomes igniarius, and Pholiota squarrosa-adiposa in media amended with manganese, calcium, zinc and iron. Mycologia 62:604-607.

30. Shigo, A. L. 1974. Effect of manganese, calcium, zinc and Fe on growth and pigmentation of Trichocladium canadense, Phialophora melinii, Hypoxylon rubiginosum, Daldinia concentrica, and Cytospora decipiens. Mycologia 66:339-341.

31. Shigo, A. L., and Sharon, E. M. 1970. Mapping columns of discolored and decayed tissues in sugar maple, Acer saccharum. Phytopathology 60:232-237.

32. Singh, G. S. 2000. Role of mineral nutrition in plant disease resistance. Growers Newsletter, Ultra Gro Plant Food Company, Madera, CA.

33. Thompson, I. A., Huber, D. M., and Schulze, D. G. 2006. Evidence of a multicopper oxidase in Mn oxidation by Gaeumannomyces graminis var. tritici. Phytopathology 96:130-136.

34. Tirajoh, A., Kyung, T., and Punja, Z. K. 1998. Somatic embryogenesis and plantlet regeneration in American ginseng (Panax quinquefolius L.). In Vitro Cell. Dev. Biol. Plant 34:203-211.

35. Wu, J. Y., and Zhong, J. J. 1999. Production of ginseng and its bioactive components in plant cell culture: Current technological and applied aspects. J. Biotechnol. 68:89-99.

36. Xu, G., and Goodel, B. 2001. Mechanisms of wood degradation by brown-rot fungi: Chelator-mediated cellulose degradation and binding of iron by cellulose. J. Biotechnol. 87:43-57. 